\title{
Development and implementation of a national service learning experience with baccalaureate nursing students: Supporting development of cultural awareness
}

\author{
Catherine S. Thomas , Leona Konieczny \\ Nursing Department, Central Connecticut State University, United States
}

Received: January 11, 2017

Accepted: March 13, 2017

Online Published: March 27, 2017

DOI: $10.5430 /$ jnep.v7n9p21

URL: https://doi.org/10.5430/jnep.v7n9p21

\begin{abstract}
This case study report provides an overview of a pilot program comprised of the concept and the value of service learning, a discussion of the development process and implementation, and shares the experiences of both the baccalaureate nursing students and faculty. This pilot program provided the opportunity for students to embody the values of the mission of the university which is centered on the development of thoughtful and responsible citizens. The department of nursing mission is congruent with this pursuit. Both missions reinforce the importance of providing students with varied opportunities to make socially significant contributions. This pilot supported the students' journey in incorporating related program outcomes of social justice with diverse population as a caring nursing professional. Providing care to residents in a culturally and geographically different location within the United States promoted a deeper understanding of cultural awareness and sensitivity and development of nursing identity. This case study discusses the implementation of the pilot which included student orientation, direct care at a mobile health clinic, and post clinic debriefings. Student feedback and faculty evaluation verified this was a positive and valuable service learning opportunity, which resulted in the decision to continue a national service learning experience annually.
\end{abstract}

Key Words: Service learning, Nursing students, Program outcomes, Cultural awareness

\section{INTRODUCTION}

The need for nurses who are culturally aware, engaged and sensitive to the diverse needs of the populations they provide care to has long been established by external and internal stakeholders of the health care system. In response to that need, implementation of various teaching methods focused on developing a foundation of cultural competence has occurred widely in nursing curricula. One teaching method that often incorporates cultural learning opportunities, is the learning pedagogy of service learning. Service learning has become increasingly commonplace in colleges and universities in the United States. Evidence has suggested that there are a variety of benefits that result from service learning. ${ }^{[1]}$ The service learning experience provided nursing students the chance to participate in a national based opportunity that emphasized the importance of civic engagement and service. The primary objective of this pilot program was for students and faculty to provide service to others. This case study re-

\footnotetext{
*Correspondence: Catherine S. Thomas; Email: csthomas@ ccsu.edu; Address: Nursing Department, Central Connecticut State University, 1615
} Stanley Street, New Britain, CT, United States. 
port provides an overview of the concept and value of service learning, discusses the development process, implementation and a summary of student and faculty experiences.

The service learning experience focused on meeting the public health needs of persons without access to health care in Appalachia. The service learning experience was exclusive from a specific nursing course, was not used as replacement for or as a designated clinical requirement. Caring for others in need actualized the mission of both the university and the department of nursing. The baccalaureate nursing program is part of a public state regional university located in the North East section of the United States. The mission of the university reads "prepares students to be thoughtful, responsible and successful citizens". [2] One of the four elements of distinction at the university is community engagement.

The mission of the department of nursing is congruent with this element. The department mission includes the development of social awareness and for students to make "socially significant and personally satisfying contributions to society". ${ }^{2]}$ The expectation of the department is that students will utilize their education to provide care that assists persons and communities to achieve optimal levels of health or wellness. The department mission further states that its future graduates will serve a wide range of citizenry with varying characteristics and needs. This expectation is again consistent with the university's vision for its graduates to contribute meaningfully to their communities as engaged professionals and citizens and to fostering societal improvements through responsive and innovative programs. ${ }^{[2]}$ The service learning experience was consistent with three nursing department program outcomes which are: "Incorporate inter- and intraprofessional communication and collaborative skills into the delivery of evidence-based, culturally sensitive patientcentered care. Provide innovative interventions to promote health and prevent illness in vulnerable populations. Practice from a caring, professional nursing perspective by incorporating the values of social justice, diversity, and global awareness". ${ }^{2]}$ Just as nursing faculty introduce and promote the concept of lifelong learning, nursing faculty should provide activities that embody the importance of lifelong service to students.

\section{Literature REVIEW}

Varied definitions of service learning exist. For this pilot program it was defined as a pedagogical approach that is experiential in nature, which intentionally supports the achievement of institution and program goals through structured reciprocal learning activities. ${ }^{[3,4]}$ Those activities provide students the opportunity to experience civic engagement and cultural awareness. With the incorporation of reflection, stu- dents are allowed the opportunity of a guided exploration of self-awareness and preconceptions that they may have had prior to the completion of service learning activities. There is the perspective that service learning and community service are interchangeable terms. Both community service and service learning provide meaningful services. The primary beneficiary of community service is the recipients. Recipients and providers are both beneficiaries of service learning. Community service can be dependent on a student's interest while service learning is tied to either a specific course or discipline of study. Service learning demonstrates benefits for students in terms of personal and social outcomes as well as career development. ${ }^{[5]}$ Faculty may benefit from having engaged students and shared experience with students. Stakeholders and volunteer organizations benefit from the services provided. An educator outside of nursing describes service learning as "community service on steroids". [6]

The components of the pilot program were more consistent with the teaching pedagogy of service learning as compared to community service. The interventions provided during the service learning experience allowed the students to engage in four of the six crucial learning attributes for service learning. ${ }^{[7]}$ The students experienced diversity of interactions, civic competencies, community activities, and critical reflection. One qualitative nursing study on service learning embedded within a course found that the students perceived the experience as challenging their understanding of self, and contributing to their becoming a nurse, and learning to care. ${ }^{[3]}$ Service learning has a positive influence on learning outcomes. ${ }^{[8]}$ Furthermore, participation in the service learning experience provided the students with experiential philanthropy. Findings in the literature demonstrate experiential philanthropy helps certain types of students to develop an awareness of social issues. ${ }^{[9]}$ These researchers found that certain types of students, female, upperclassmen, and those in helping professions, benefited more than others from service learning. ${ }^{[9]}$ This study also documented that students' perceptions of service learning may be positively affected by the involvement with the group and with faculty. ${ }^{[9]}$ The faculty who accompanied the students also engaged in direct care which demonstrated theory put into practice.

\section{DEVELOPMENT OF PILOT PROGRAM}

Operationalizing the pilot program required the development of a proposal that explained the intent and goals of the pilot, a tentative budget, information about the volunteer organization, timeline and implementation plans, as well as how students were going to be selected. A non-profit volunteer organization that offers short term mobile medical clinics nationally and internationally to underserved populations had 
been identified by the faculty as having congruent mission, and accepted nursing students as direct care participants. Review and approvals from various stakeholders at the nursing department, academic dean, and university levels was necessary. One stakeholder asked for testimonials from outside nursing faculty who had experience with students and the identified volunteer organization, and once that was provided, gave their approval. Funding was provided by a local private scholarship foundation that granted permission to utilize the funds for lodging and transportation.

The proposal was to attend a two day mobile medical clinic which offered medical, vision and dental care free of charge, in a small town which is part of Monroe County located in rural eastern Tennessee that has been designated as part of the Appalachian region by the Appalachian Regional Commission. ${ }^{[10]} \mathrm{A}$ total of ten students participated in the mission trip; each day of the clinic, one group of five students were able to attend and participate in the clinic along with a faculty member who provided oversight and supervision which was outlined and required by the volunteer organization.

\section{Program implementation}

The service learning experience was completed over a four day period in late spring. There were several influencing factors; available spring clinics scheduled by the organization, major religious holiday at the end of spring break, and the need to validate that students were meeting clinical objectives for the spring semester.

The university student activities and leadership development department assisted in completion of required documentation along with travel arrangements. The students were only responsible for limited number of meals as many meals were provided at the motel or clinic.

\subsection{Student selection}

The volunteer organization limited the number of participants able to volunteer. Based on literature and identified resources, an application and selection process were developed and presented to junior level nursing students. The application consisted of a summary of employment and volunteer history and one page essay describing their motivation and skills. In addition, students needed to demonstrate satisfactory academic standing in the nursing courses. The student selection process was reached by faculty consensus after a review of the applicant materials at a departmental meeting.

\subsection{Orientation for students}

Prior to departure, the entire group of students and faculty met for an orientation session; which included an overview

Published by Sciedu Press of the region, behavioral and professional expectations along with travel logistics.

\subsection{Provision of care}

Each group began their clinic day in triage, collecting pertinent health history information and obtaining baseline vital signs. Whenever possible, basic health teaching was reviewed to promote a healthier lifestyle. Once the majority of the patients were processed, the students volunteered in several different ways to support the medical, dental and vision services delivered. The students were able to interact with both patients and other volunteers about many topics, touching upon various cultural experiences. Students were able to dialogue with inter-professional health care volunteers from across the country.

\subsection{Cultural learning}

The Appalachian region is predominantly rural, and despite moderate gains from various public and private interventions, the poverty rate for many counties in Appalachia continues to be significant. ${ }^{[10]}$ The students were exposed to profound regional differences, as the county that the clinic was located in has a poverty level of $20.6 \%$, with $17.6 \%$ of the population under the age of 65 who do not have health insurance. In comparison, the county that the university is located in and where the majority of clinical experiences occur, has a poverty rate of $12.2 \%$ for individuals and for children (under 18 ) of $17.9 \%$, with $10.3 \%$ of the population under the age of 65 who do not have health insurance. ${ }^{[11]}$ There are four distinct people groups of descendants from the first settlers in Appalachia; industry workers (coal, logging, or factories), professionals, and returning Appalachians. ${ }^{[12]}$ Professionals who choose to move to the area for employment are sometimes referred to as "outlanders". ${ }^{[12]}$ The patients served in the clinic were not professionals but persons such as descendants and workers without access to healthcare due to economic reasons. Nursing students benefited from experiencing the culture expressed through traditional foods, customs, and language patterns. However, it was the expectation that nursing students appreciated the uniqueness of each patient and avoid stereotyping.

\subsection{Debriefings}

At the end of each clinic day, the students and faculty debriefed through group sharing and reflection, and discussed challenges and strengths of the health care system and the clinic. On the alternate day, the groups experienced different local attractions and activities, immersing them in the regional culture. The majority of the students and both faculty met on campus several days after returning, and engaged in another debriefing session. 


\section{DisCussion}

The students verbalized a deeper understanding of culture awareness, intercultural sensitivity, and nursing identity. The students shared multiple interactions and observations that raised their cultural awareness. Students recognized the impact of health care disparities through interactions with individuals and families that attended the clinic. Faculty witnessed the students' internalization of service into their professional nursing identity. Observations of the faculty of both student groups included a high level of engagement with both clinic attendees and other volunteers, in addition to a demonstration of flexibility in meeting the changing needs of the clinic as the day progressed. Both faculty identified that the students consistently exemplified professional nursing behaviors.

Student feedback verified this was a positive and valuable learning experience. They expressed the perspective that a continuation of this opportunity in upcoming academic years would be of significant benefit. Structuring this service learning experience separate from specific course or clinical requirements reinforced both the university and department missions and program outcomes. With the positive outcome of this pilot program, the second service learning experience is planned. It has been extended to a week-long encounter with multiple settings for providing service to others, along with time to experience the local culture. The positive feedback from students and faculty reinforces the importance of maintaining a national service learning experience. There are areas in America that present with distinct cultural differences and need for healthcare services. The intent is with continued support from stakeholders within the university and nursing department to continue with service learning experiences long-term.

\section{CONFlicts of InTERest Disclosure}

The authors declare that there is no conflict of interest.

\section{REFERENCES}

[1] Toncar MF, Reid JS, Burns DJ, et al. Uniform assessment of the benefits of service learning: the development, evaluation, and implementation of the SELEB scale. Journal of Marketing Theory and Practice. 2006 summer; 14: 223-238.

[2] Central Connecticut State University. [Internet]. New Britain: Central Connecticut State University; 2016 [cited 2017 Jan 12].

[3] Stallwood LG, Groh CJ. Service-learning in the nursing curriculum: Are we at the level of evidence-based practice? Nurs Educ Perspect. 2011 September/October; 32(5): 297-301.

[4] Schofield R, Allan M, Jewiss T, et al. Knowing self and caring through service learning. Int J of Nurs Educ Scholarsh, 2013; 10(1): 267-274.

[5] Bandy J. What is Service Learning or Community Engagement? [Internet]. c2016 [cited 2017 Jan 12]. Available from: https: //cft.vanderbilt.edu

[6] Turner R. What is the difference between community service and service learning [Internet]? Ann Arbor: Michigan State Univer- sity Extension; 2012 [cited 2017 Jan 12]. Available from: http: //msue.anr.msu.edu/

[7] Hahn T, Hatcher J, Price M, et al. IUPUI Taxonomy for Service Learning Courses [Internet]. c2015 [cited 2017 Jan 12]. Available from: https://scholarworks.iupui.edu

[8] Warren JL. Does Service-Learning Increase Student Learning? A Meta-Analysis. Michigan Journal of Community Service Learning. 2016 spring; 18(2): 56-61.

[9] McDougle L, McDonald D, Li H, et al. Can Philanthropy Be Taught? Nonprofit Volunt Sect Q. 2016; 1-22.

[10] Appalachian Regional Commission [Internet]. Office of the Inspector General; no date [cited 2017 Jan 12]. Available from: https : //www.arc.gov/index.asp

[11] United States Census Bureau [Internet]. US Department of Commerce; no date [cited 2017 Jan 12].

[12] Appalachian Culture [Internet]. North American Mission Board; no date [cited 2017 Mar.2]. 